\title{
Placing Energy Efficiency at the Forefront of Corporate Strategy
}

\author{
Lucas NG Hong Kiang \\ Petrochemical Corporation of Singapore (Private) Limited, 100, Ayer Merbau Singapore 628277, Singapore
}

Received: July 29, 2016 / Accepted: August 16, 2016 / Published: December 31, 2016.

\begin{abstract}
In the last four decades, there were several energy crises caused by various factors including peak oil production in major industrial nations where energy price increased due to shortage in supply. Back then, energy efficiency improvement was a big subject to conserve energy. Today, over $80 \%$ of current energy needs are derived from fossil fuels, and with the low crude oil price of USD45 per barrel there is no conservation incentive for energy users. However, climate change caused by already accelerated emission of greenhouse gases into the Earth's atmosphere would be aggravated by a combination of low oil prices and abundance of supply. Therefore, corporations should start energy efficiency campaigns for the purpose of combating climate change by reducing greenhouse gas emissions especially for process plants with large energy consumption. The campaigns should include energy management, use of high energy efficient equipment and systems that monitor and optimize the use of energy. Energy benchmarking exercises would help to check and monitor energy efficiency performance level for continuous improvement.
\end{abstract}

Key words: Efficiency, emission, greenhouse gas, investment, optimization.

\section{Introduction}

Climate change is a reality today. From the extreme weather conditions and changes, to the impact on agriculture yield, and to diseases breaking out due to increased activity of certain viruses. The latest outbreak of Zika virus in Latin America [1] is said to link with climate change. Investigation is still ongoing to confirm this potential link.

There have been differing opinions on the contributors of global warming in the past many years. There are natural causes which contribute to climate change. These natural causes refer to variation of sun's energy reaching Earth, changes in the reflectivity of Earth's atmosphere and surface, and changes in greenhouse gas effect [2]. However, recent trends in climate change cannot be explained by natural causes alone.

Corresponding author: Lucas NG Hong Kiang, B.Sc. chemical engineering, general manager of plant.

\section{Contribution of Industrial Activities to GHG Emissions}

It is well established that the main GHG (greenhouse gases) refer to carbon dioxide $\left(\mathrm{CO}_{2}\right)$, methane $\left(\mathrm{CH}_{4}\right)$, nitrous oxide $\left(\mathrm{N}_{2} \mathrm{O}\right)$, and others. Some other GHGs are water vapour, ozone $\left(\mathrm{O}_{3}\right)$ and chlorofluorocarbons (CFCs). According to the United States EPA (Environmental Protection Agency), atmospheric $\mathrm{CO}_{2}$ concentrations have increased by more than $40 \%$ since pre-industrial times in the 18th century, mainly from burning of fossil fuel and petroleum derived products during disposal by burning.

Global $\mathrm{CO}_{2}$ emissions from fossil fuels have significantly increased since 1900 . For the last five decades, $\mathrm{CO}_{2}$ emissions have increased by approximately $90 \%$ [3]. With the growth in global population and economic activities, the GHG emissions are expected to continue rising in the coming years.

\section{Current Major Energy Source: Fossil Fuels}

Today, over $80 \%$ of energy needs is derived from 
fossil fuels such as coal, oil and gas. The situation will not change significantly over the next decade subject to the viability of renewable energy sources at various locations and their respective technological advancement [4].

\subsection{Energy Source and Cost}

Energy source and its costs directly affect economic competitiveness as well as environmental sustainability. Currently the oil price has dropped to the low level of USD45 per barrel. The lower oil price was the result of oversupply in the market as oil producers maintained production levels in order to retain their market shares. The downside of lower oil price is that people lose the sense of urgency for energy conservation because of lowered incentive, and neglect the fear of energy security. This endangers the challenge of energy efficiency drive as well as research and development to address the energy "trilemma" of energy security, economic competitiveness and environmental sustainability.

\subsection{Industry Fossil Fuels' GHG Emissions}

The EPA's 2010 global greenhouse gas emissions data indicate that $21 \%$ of emissions are from industry as this sector primarily involves fossil fuels burned onsite at facilities for energy. This has not included the emissions contributed by electricity consumption and the fuel used to generate it [3].

\subsection{Chemical and Petrochemical Sector}

The chemical and petrochemical sector is a large energy consumer, taking the significant share of more than $30 \%$ of total energy use worldwide [5]. Within this sector, the petrochemical industry is responsible for $70 \%$ of fuel expenditure and $40 \%$ of electricity [6]. Being the high energy consumer, a relatively small improvement of energy efficiency of petrochemical facilities can translate to a significant reduction in the industry's carbon footprint.

\section{Energy Efficiency by the Practical Approach}

Climate change caused by already accelerated emission of GHG into the Earth's atmosphere with increasing global energy demand would be aggravated at low oil prices coupled with abundance in supply. Therefore, an energy efficiency campaign is the practical and cost-effective means of mitigating GHG emissions while sustaining economic growth [7]. It is also a common goal to optimize and conserve the use of limited energy source reserve of fossil fuels.

For industry of large energy consumption, stakeholders should take on bird's eye view of energy efficiency improvement activities starting from the quick-fix to the more complex categories. It is crucial to take steps towards becoming more energy efficient instead of bogging down by budget constraints.

\section{Large Energy Consumers to Take Lead}

It is logical to have large energy consumers to lead in slowing down the rate of global warming as a small improvement could result in a large absolute reduction in GHG emissions.

\subsection{Adopting Best Practices and Emerging Technology}

The current technology has evolved over the last few decades. In process plants there are heat transfer technologies that are efficient in reducing specific energy consumption. High efficiency proprietary heat transfer equipment and processes are available. Heat integration by advanced recovery system or the heat cum material transfer integrated rectifier system [8], heat pump system and improved compressor design have emerged in the last two decades. This newer technology is generally highly energy integrated with more complex process streams inter-related to each other units.

The utility power facilities which support the process plants are equipped with gas turbine power generators and waste heat boilers. They have in turn combined the thermal cycle which has improved the 
overall energy efficiency. This new development in technology has become the norm.

\subsection{Use of Variable Speed Driver}

For gas turbines and steam turbines as drivers of rotating equipment such as compressors and electric generators, the speed of the drivers [9] can be controlled efficiently. However, it is not the case for electric motors as they are drivers without speed controllers.

The electric motor's driving components, such as the pump, compressor and blower, normally operate at a constant speed. Some form of mechanical throttling is used to control the process conditions such as a valve on the outlet, inside the case of a pump and compressor, or the slats in a louver and within the case of a blower. Using such controls, the electric motor continues to operate at full speed and uses excess electric energy compared to optimal levels. It wastes a great deal of energy. To adjust the rotational speed of a motor, a VFD (variable frequency drive) can be applied.

The VFD is a device which controls the voltage and frequency of the current being supplied to a motor in meeting the power demand by the varying load of the process stream. This is to ensure the driver is operating optimally with efficient energy consumption. The potential savings in electric energy can be as high as $50 \%$ [10]. The measure to meet such requirement is also known as MEPS (Minimum Energy Performance Standards).

\subsection{Multiple Small Improvements Add Up to Big Reductions}

An energy efficiency campaign can start from small and quick-fix improvements. Some realizable energy savings examples may be summarized as follows:

(1) Timely rejuvenation or replacement-the process plant inefficiency could be attributed to aged and/or fouled heat transfer equipment. The aging of process equipment could also be caused by corrosion or erosion related issues such that part of the heat transfer equipment is required to be partially blocked off in order to minimize downtime. Therefore timely rejuvenation or replacement of aged process equipment would restore its energy efficiency.

(2) Use of effective chemical inhibitors for process fouling - certain chemical processes of petrochemical and related industry tend to cause fouling to their heat transfer equipment. The fouled equipment would result in inefficient heat transfer consuming higher specific energy. Using the correct and effective fouling inhibitors, such as radicals terminating chemicals, could effectively reduce or even stop equipment from fouling by terminating polymerization of radicals.

(3) Emerging cleaning technologies - certain process heat transfer equipment in process plants are located at locations with difficult access for heat recovery. Most of such equipment are also equipped with external fins element to enhance heat transfer coefficient, and are susceptible to fouling by foreign materials over time. Very often, the inefficiency of such equipment is left unattended for a considerable of time. Adopting of new cleaning technology such as the use of dry ice would ease the cleaning effort to restore energy efficiency. Such technologies could cover a wide range of equipment such as steam boilers, cracking furnace's finned heat exchangers, air fin coolers etc.

(4) Minor retrofit-addition of heat transfer equipment to existing process plant is another practical solution in recovering otherwise lost energy. The fact is that process plant operating conditions might be deviated from their original design intent due to various reasons such as changes in feedstock. Such retrofit is usually of smaller scale with some could be done even during on-stream operation. One typical retrofit is the addition of preheat coil at the exhaust flue gas path of process furnace for waste heat recovery as the individual furnace of multiple trains could be shut down for maintenance.

\section{A "Second-Tier" of Return on Investment or Internal Rate of Return}

For major process unit retrofit, the existing processes 
can be improved via heat integration combining with low approach temperature heat transfer equipment, high efficiency rotating equipment and even heat pump system. The main goal is to recover waste energy that is lost to the atmosphere due to inefficiency such as a condensing steam turbine. However, the capital expenditure for such energy efficiency projects is usually high with very marginal traditionally acceptable level of ROI (return on investment) or IRR (internal rate of return) compared to that for production capacity increase. Quite often such proposals are rated low in the corporate investment criteria.

Energy efficiency projects ROI or IRR would become worst when the crude oil price is low such as at current level of USD45 per barrel.

To realize high energy consumption reduction for lowering GHG emissions, one has to consider a "second-tier" ROI or IRR corporate criteria different from that of capital projects. Such energy efficiency projects could be financed and structured to insure the monthly payment is less than the energy savings realized [11]. This must be supported by the stakeholder with governmental incentive that promotes energy-efficient investment.

\section{Process Optimization and Energy Efficiency Monitoring}

Having the best combination of energy efficient process equipment in place process plants without optimal operating parameters would also result in energy inefficiency. Substantial energy savings with reduced GHG emissions could be realized by adopting automation systems for advanced process control with optimization feature.

\subsection{Process Optimization}

Process optimization utilizing computer software is widely used in process plants to achieve their optimization objectives. The implementation of real-time and off-line optimization in process plants has multiple benefits. First of all, it improves yield of processing certain known quality feedstock. It also reduces product quality give-away and specific energy consumption amid more steady process conditions, with less maintenance and even eliminate unplanned shutdown.

Indeed, the advanced process control at individual process unit level is already able to reduce energy consumption significantly, and yet increase production rate by reducing impurity fluctuation bandwidth of as much as $50 \%$.

\subsection{Energy Efficiency Monitoring}

In chemical process plants, especially the upstream petrochemical plant, the operation is supported by a wide range of utilities including energy facilities. The common sources of energy are steam, electricity and fuel. The steam supplies are usually of various energy levels associated with water condensate, complementing electricity, fuel and other utility supplies. Such utilities can either import from external sources or generate internally. The efficient use of such energy sources is closely related to the performance of process plants, and is dynamic in nature.

As the key concerns for energy management in view of the ever-changing energy market together with the process plant constraints for process optimization, separate computer optimization software on utilities is required. This utilities optimization [12] software is to assess and monitor energy efficiency on continuous basis more effectively independent from that of process optimization. Process plant energy costs can be reduced as much as 3 to $5 \%$, depending very much on the optimization level of process units.

\section{Benchmarking for Continuous Improvement}

On the path of continuous improvement, one would ask, "How are we doing?", "How do we know our energy savings performance?" Internal comparisons, for instance, reviewing the trend data over the improvement periods and evaluating them are essential 
but there is limitation. Therefore, benchmarking with similar process units or plants with other companies through certain renowned benchmarking agency [13] is the best answer to these questions. Such agency has accumulated data over a certain period with large sample size by participating companies that could provide useful information and the level of achievement. The benchmarking outcome can be in terms of being at certain quartile level, and its position amongst the participating companies, and advice for areas of improvement. Such energy benchmarking should have been imbedded in the overall process plant performance benchmarking if conducted.

\section{Conclusions}

The stakeholder's commitment to strategize its energy management program is crucial for the success of improving energy performance of existing facilities. Stakeholders should take a bird's eye view in implementing various categories of improvement within their facilities. These include the use of high energy efficient equipment for new installations, and to rejuvenate and replace aged equipment for energy recovery. It needs not to be bogged down by just exploring major projects but can begin with humble and small multiple improvements with realizable energy savings. A mindset change in energy efficiency projects is essential by adopting a "second tier" ROI, a different treatment from capital projects. The determination to achieve the energy efficiency improvement, seeking relevant supports and advice, would certainly arrive at the set goals. With the best combination of energy efficient process equipment in place, it also requires process optimization control systems compliment with energy benchmarking exercises to check and monitor energy efficiency performance level for continuous improvement.

\section{References}

[1] Americas News \& Top Stories. 2016. "Climate Change Linked to Zika Outbreak.” The Straits Times, February 8.
[2] EPA. "Causes of Climate Change." United States Environmental Protection Agency. February 2016. http://www3.epa.gov/climatechange/science/causes.html.

[3] EPA. "Global Greenhouse Gas Emissions Data." United States Environmental Protection Agency. February 2016. http://www3.epa.gov/climatechange/ghgemissions/global. html.

[4] Browne, J. "Proposal-The Energy Crisis and Climate Change". http://www.global-economic-symposium.org/ knowledgebase/the-global-environment/the-energy-crisisand-climate-change/proposals/the-energy-crisis-and-clim ate-change.

[5] Saygın, D., Patel, M. K., Tam, C., and Gielen, D. J. 2009. "Potential of Best Practice Technology and Other Measures for Improving Energy Efficiency, Chemical and Petrochemical Sector." International Energy Agency, OECD/IEA 2009.

[6] Neelis, M., Worrell, E., and Masanet, E. 2008. "Energy Efficiency Improvement and Cost Saving Opportunities for the Petrochemical Industry." The US Environmental Protection Agency (EPA).

[7] Singapore National Environmental Agency's website. "Energy Efficiency in Singapore-Energy Efficiency is a practical and cost-effective means of mitigating carbon dioxide emissions while sustaining economic development. As an open economy with no natural resources, Singapore is vulnerable to rising energy costs that can affect our economic competitiveness. It is therefore crucial that we take steps towards becoming more energy efficient." January 2016. http://www.nea.gov.sg/events-programmes/campaigns/en ergy-efficiency-singapore.

[8] Stone \& Webster, Inc. 2001. Advanced heat integrated rectifier system. US Patent US6,343,487.

[9] Westerkamp, T. A. 2008. "Variable-Speed Drive: An Energy-Efficient Solution.” Facilities Net. January 2016. http://www.facilitiesnet.com/energyefficiency/article/Dri ving-Energy-and-Cost-Savings--8930.

[10] Spiesshofer, U. "ABB Ltd Energy Efficiency Is by Far the Best Way to Tackle Climate Change." February 2016. https://www.ies.org.sg/publication/se/jan16.pdf.

[11] Zobler, N. 2009. "Energy Efficiency Is a Good Business Decision, Especially Now!” February 2016. https://www.energystar.gov/ia/partners/spp_res/NEMA\% 20Article\%20Feb\%202009.pdf.

[12] Utilities Optimization, SimSci ROMeo Online Performance Suite. http://software.invensys.com/ products/simsci/optimize/romeo-utilities-optimization/.

[13] Benchmarking for the Chemicals Industry, Solomon Associates. https://www.solomononline.com/ benchmarking/chemicals. 